\title{
Experimental Analysis of carbon fiber reinforcement T-Shaped stiffened composite Cleat/Panel with aluminum panel using UTM
}

\author{
Ravindra Jambhorkar*, K.M. Nawasagare ${ }^{\#}$, Subim Khan ${ }^{\circledR}$, A.M. Badadhe ${ }^{\$}$ \\ *PG Design Engg. Student, JSPM'S Rajarshi Shahu College of Engineering Pune \\ \#@\$ Mechanical Engg Department, JSPM’S Rajarshi Shahu College of Engineering Pune
}

(Received 21 September 2020; Accepted 5 May 2021)

DOI: https://doi.org/10.36224/ijes.140204

\begin{abstract}
T-shaped composite cleat are used in thin walled structures including aircraft fuselage with wings, with the skin carrying membrane loads and the stiffeners carrying bending loads and resisting skin buckling. The project includes T-shaped stiffened Aluminum cleat will be used for analysis purpose along with Carbon fiber composite reinforcement T-stiffened composite cleat. The carbon fiber reinforced T-stiffened panels were manufactured with carbon fiber arranged in a [45/0/45/0/45] s ply pattern. The model of T-stiffened composite reinforces panels and T -stiffened Aluminum panel is made in Catia V5R20. Static structural of specimen will be perform using ACP tool in ANSYS 19 software. In experimentation, tensile test of both specimens have been performed on UTM. The comparative analysis was carried out between the Analytical and experimental results. After manufacturing, the comparative analysis result and conclusion was drawn.
\end{abstract}

Keywords: ANSYS, CATIA, COMPOSITE, UTM

\section{Introduction}

In modern era of engineering everybody is looking for better solution for every problem. The reinforcement is technique widely used in every industries likely automobile and aeronautics. This is point motivated by the concept that such cleats have the power of producing highly efficient structures with governing their mechanical properties along with performance, allowing them an adequate force transfer with load bearing capacity. Currently $\mathrm{T}$ - shaped composite stiffened cleat are employed in fuselage components and wing panels on aircrafts, among other applications.

In many cases we observed delamination scale in these specimens, the effects such damage can be either confined to a local region, affecting the actual stiffness of the specimen, or can lead to catastrophic failure

\section{Literature review}

A.P. Herman et.al.(1) The numerical and experimental analysis into the discovery of flaws in composite T-shaped stiffened cleat using vibration modal analysis. This study was made on carbon fibre/epoxy laminate cleat containing a delamination crack or porosity. Experimental analysis exposed that vibrational excitation of the defective panels altered the vibration mode response, which was measured using scanning laser vibrometer. The MSC-difference outline method was also revealed to find localised porosity and the bond-line, the location cannot be determined. The accuracy of the MSC-difference method to predict damage was maximum with the method of the lowest vibration mode. 
Shen Shang et.al.(2) This analysis contains of two key parts modal analysis of undamaged (FE) model and damage model at single otherwise multiple locations, there is no experimental study for composite which is laminated structures.

I. Herszberget.al (3) Cad Model and testing of a typical glass fibre reinforced composite Tshaped joint, which is subjected to disbands at many borders was presented. Optical fibre Bragg grating sensors to control the strain distribution for operational loads or, the Ran-Dec signature for environmental arbitrary disturbances.

J. Justo et.al (4)The study shows failure of carbon fiber reinforced polymer (CFRP) composite cleat. On other hand, for coupons Type-B, the start location grabbed underneath the deltoid by the interface among the outermost 45 degree layer and the contiguous layer, and travelled towards adhesive layer close the flange edges. The piling sequence measured the crack relocation path. The presence of a 45_-45_ layers at the attachment line for specimens Type-A-1 and Type-B-1 requires cracking both in order to connect the interface with the outermost 90 ply

D. Quinn et.al (5) the researchers made analysis and studied the constraints during manufacturing. They have studied the impact of material while reinforced. They have also studied \& analysed different parameters like weight, geometry constraints etc. They observe that reinforce material will show more flexibility toward external loads. The reinforce structure will have to be more resistance power towards external applied load.

\section{Objectives}

3.1 To understand the strengths along with limitations of existing T-shaped stiffened panel.

3.2 Tensile strength of T -shaped-stiffened Aluminum cleat and T-shaped -stiffened composite reinforce cleat is to be analyzed.

3.3 Static structural analysis has to be done.

3.4 To perform Tensile test in UTM.

3.5 To compare \& plot result value.

\section{Methodology}

Step 1:- We have collected all research paper \& data of analysis.

Step2:- We have selected the component for testing.

Step 3:- We have modeled the 3Dcomponent in CATIA software.

Step 4:- We have used ANSYS software for modal analysis.

Step 5:- The component has experimentally tested

Step 6:- We have compared the result \&drawn conclusion.

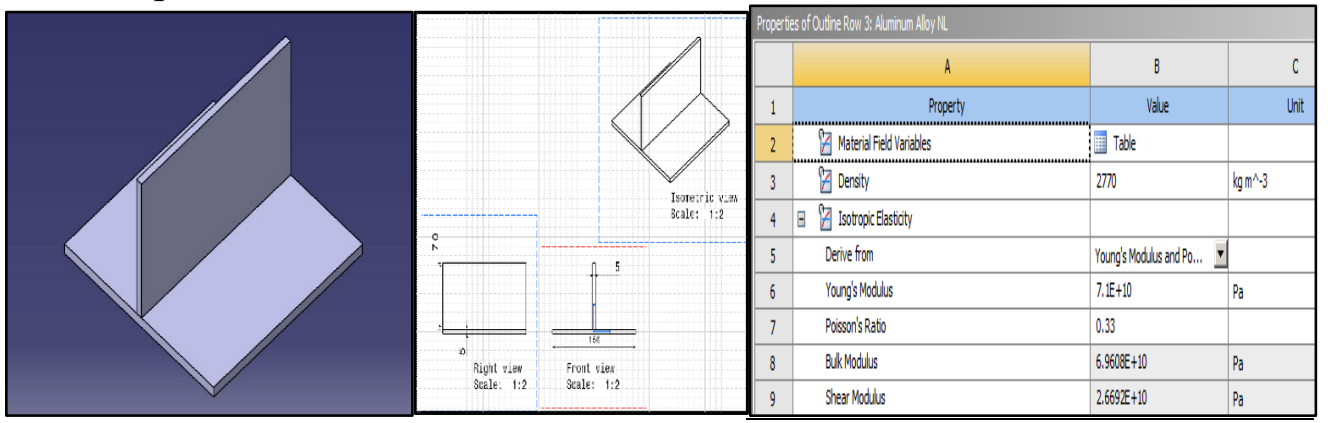

Figure 1: Catia and drafting of $\mathrm{T}$ joint and material properties 


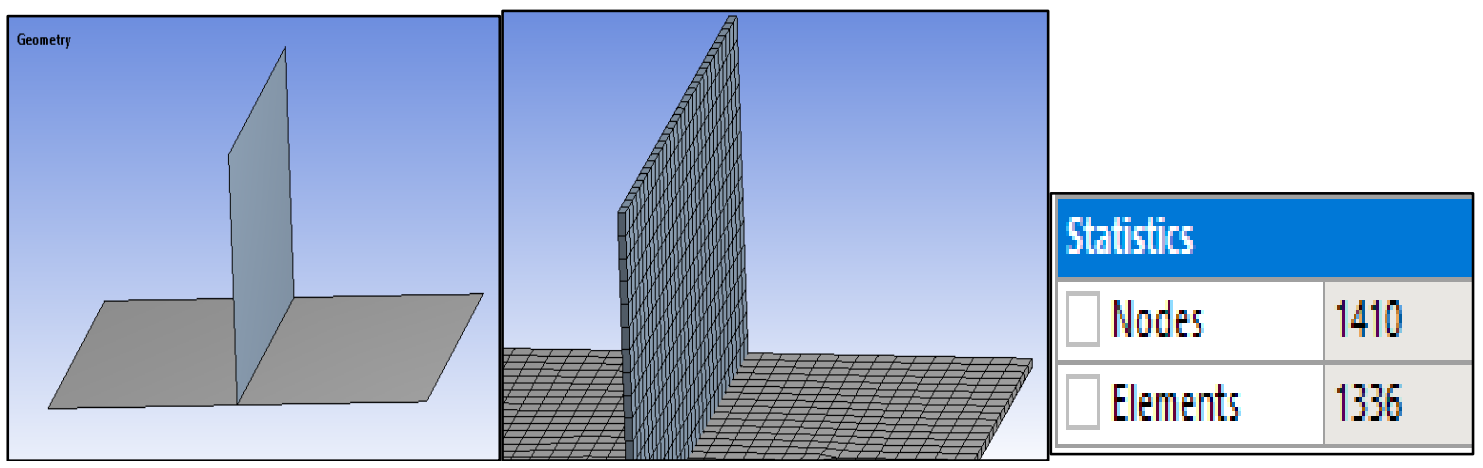

Figure 2: Geometry imported in ANSYS Figure.3: Geometry and details of meshing of T joint

\subsection{Mesh}

ANSYS Software has used for meshing. The automated parallel mesh is used to ensure load transfer.

\subsection{Boundary Condition}

A boundary condition for the model is that the setting of a well-known value for a displacement or an associated load. For a specific node you'll be able to set either the load or the displacement but not each. The main kinds of loading obtainable in FEA include force, pressure and temperature. These may be applied to points, surfaces, edges, nodes and components or remotely offset from a feature.

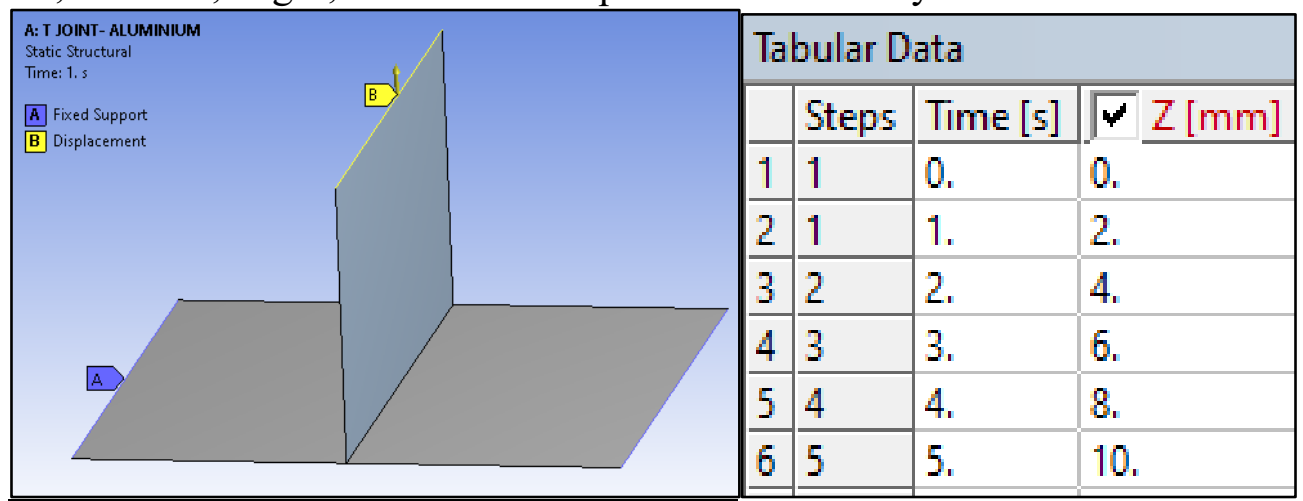

Figure 4: Equivalent plastic strain results

Fixed supports are applied at edges of plate and displacement of $10 \mathrm{~mm}$ is provided at top edge in step of 5 with $2 \mathrm{~mm}$ each.

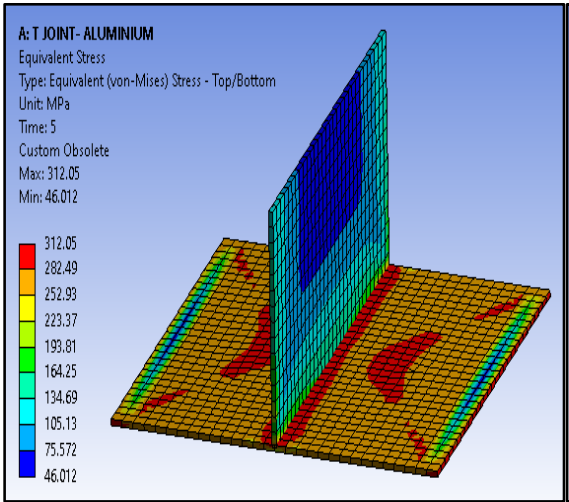

Figure 5: Equivalent stress

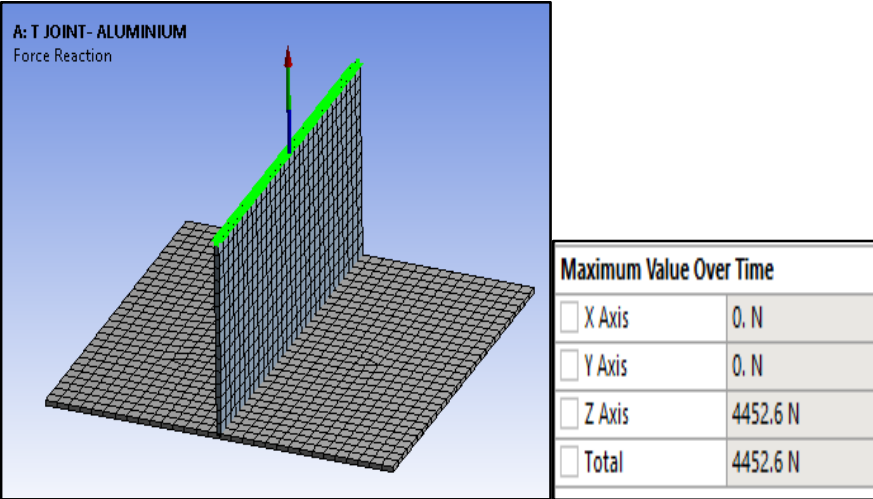

Figure 6: Reaction force results 


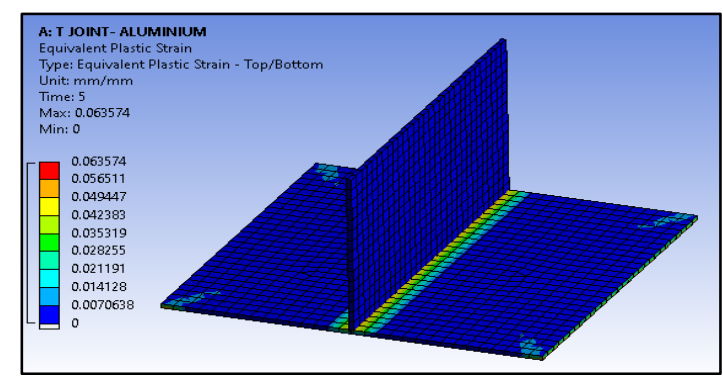

Figure 7: Equivalent plastic strain results

4.2.1. T-joint with aluminum and carbon epoxy reinforcement

\subsubsection{Engineering material properties}

\begin{tabular}{|c|c|c|c|}
\hline \multicolumn{4}{|c|}{ Properties of Outhe Row 4: Epoxy Carbon UD (230 GPa) Prepreg } \\
\hline & A & B & c \\
\hline 1 & Property & Value & Unit \\
\hline 2 & Density & $1.49 E-09$ & $m m^{\wedge}-3 t$ \\
\hline 3 & I $\begin{array}{l}\text { Orthotropic Secant Coefficient of Thermal } \\
\text { Expansion }\end{array}$ & & \\
\hline 8 & 曰 7 Orthotropic Elasticity & & \\
\hline 9 & Young's Modulus X direction & $1.21 E+05$ & MPa \\
\hline 10 & Young's Modulus Y direction & 8600 & $\mathrm{MPa}$ \\
\hline 11 & Young's Modulus Z direction & 8600 & MPa \\
\hline 12 & Poisson's Ratio XY & 0.27 & \\
\hline 13 & Poisson's Ratio YZ & 0.4 & \\
\hline 14 & Poisson's Ratio XZ & 0.27 & \\
\hline 15 & Shear Modulus XY & 4700 & MPa \\
\hline 16 & Shear Modulus YZ & 3100 & MPa \\
\hline 17 & Shear Modulus XZ & 4700 & $\mathrm{MPa}$ \\
\hline
\end{tabular}

\begin{tabular}{|c|c|c|c|}
\hline Layer & Mateid & Thicknes (mm) & Angle? \\
\hline \multicolumn{4}{|l|}{$(-2)$} \\
\hline 4 & Epoxy Garton UD (2006Pa) Prepereg & 1 & 90 \\
\hline 3 & 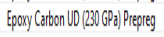 & 1 & 45 \\
\hline 2 & Epooy Grobon UD (2006Pa) Prepleg & 1 & 0 \\
\hline 1 & Aluminum Allog NLL & 2 & 0 \\
\hline (-2) & & & \\
\hline
\end{tabular}

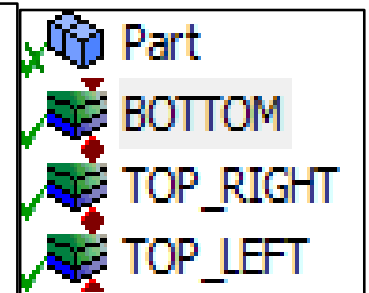

Figure 8: Details of composite layer pile up conditions

\subsubsection{Composite layers}

- The three layer composite $\mathrm{T}$ - joint prepared

- Total thickness is $5 \mathrm{~mm}$ so, aluminum alloy $-2 \mathrm{~mm}$, epoxy carbon $(1 \mathrm{~mm})$ with $0^{0}$, epoxy carbon (1 $\mathrm{mm})$ with $45^{\circ}$ and epoxy carbon $(1 \mathrm{~mm})$ with $90^{\circ}$.

- $\left[0^{0}, 45^{0}, 90^{\circ}\right]$ are ply orientation angle which are the bestfiber angle location in composite layer concept.

- So, these locations of fiber are provided layer by layer and reinforcement is done.

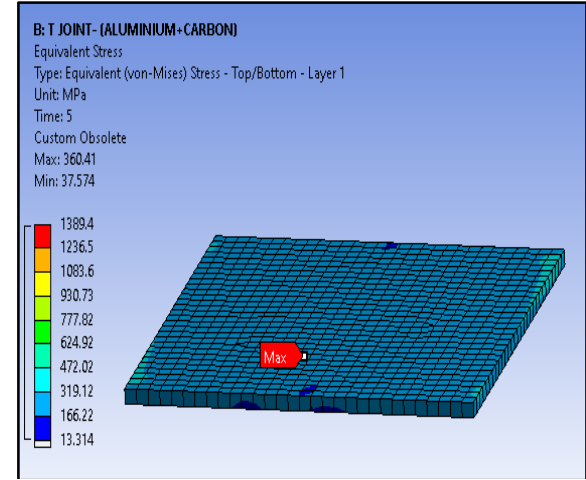

Figure 9: Equivalent stress on bottom layer results

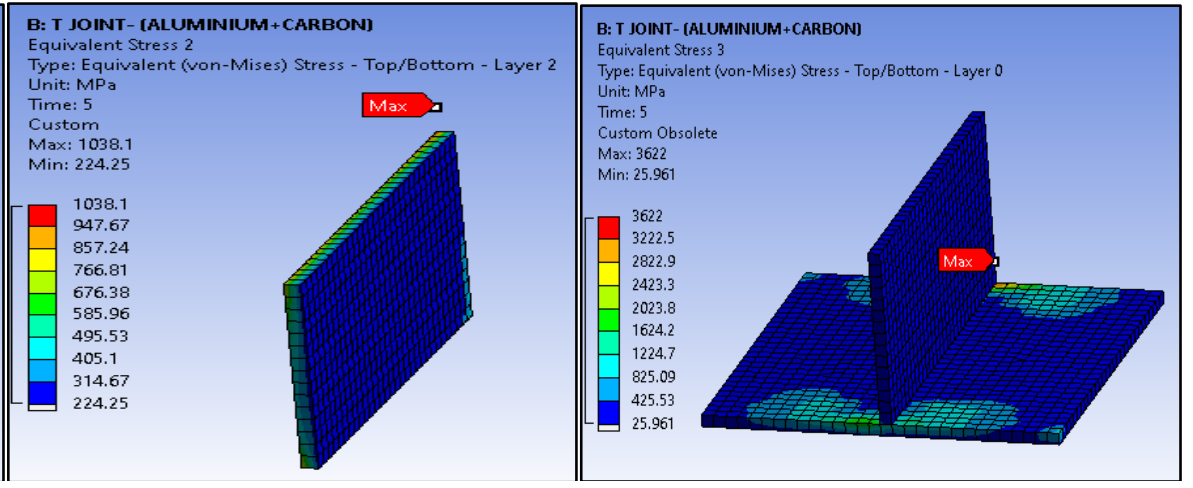

Figure 10: Equivalent stress results for different layers 


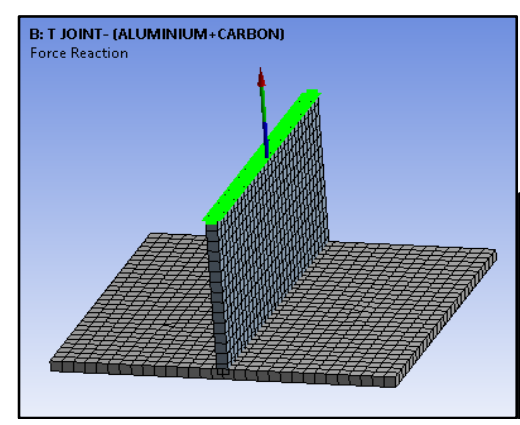

Figure11: Reaction force results for composite material

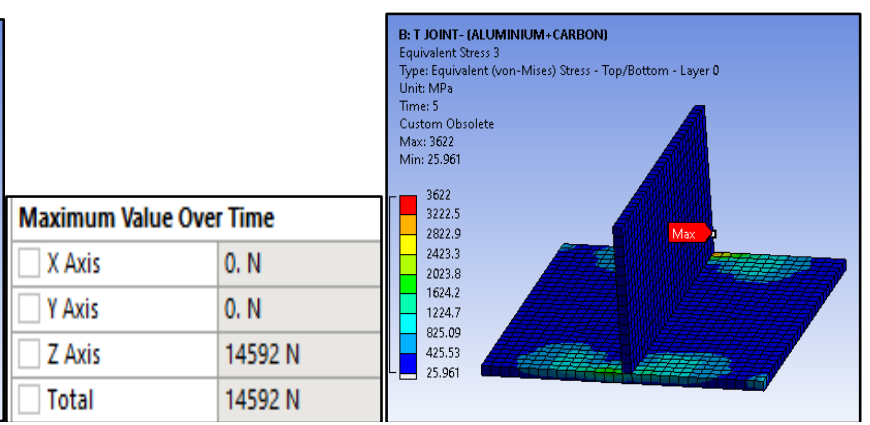

Figure12: Equivalent stress results for different layers

We observed that T-shaped reinforced cleat develop force to $14.592 \mathrm{KN}$ as compared to existing $\mathrm{T}$ shaped joint with aluminum material with $4.452 \mathrm{KN}$.

\subsubsection{Experimental setup}

We have used a universal testing machine (UTM), also known as a universal tester, the machine is used to determine the tensile \& compressive strength. it is also called as a tensometer. The standard specimen are held by fixture \& we have increased load intensity gradually \& observed the changes. The change in length has been observed along with corresponding load have been recorded. The UTM has provision to record all parameters.

\subsection{Specification of UTM}

Table 1: Specification of UTM

\begin{tabular}{|l|l|l|}
\hline 1 & Max Capacity & $400 \mathrm{KN}$ \\
\hline 2 & Measuring range & $0-400 \mathrm{KN}$ \\
\hline 3 & Least Count & $0.04 \mathrm{KN}$ \\
\hline 4 & Clearance for Tensile Test & $50-700 \mathrm{~mm}$ \\
\hline 5 & Clearance for Compression Test & $0-700 \mathrm{~mm}$ \\
\hline 6 & Clearance Between column & $500 \mathrm{~mm}$ \\
\hline 7 & Ram stroke & $200 \mathrm{~mm}$ \\
\hline 8 & Power supply & 3 Phase , 440Volts , 50 cycle. A.C \\
\hline 9 & Overall dimension of machine $\left(\mathrm{L}^{*} \mathrm{~W}^{*} \mathrm{H}\right)$ & $2100 * 800 * 2060$ \\
\hline 10 & Weight & $2300 \mathrm{Kg}$ \\
\hline
\end{tabular}

\subsection{Experimental FEA}

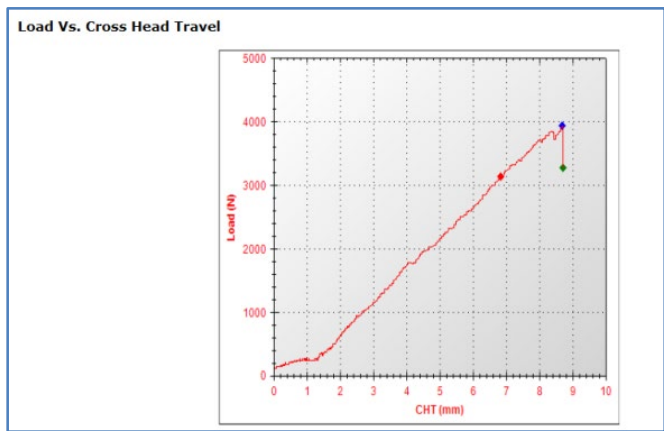

Figure13: load vs cross head 


\subsubsection{For $\mathrm{T}$ joint aluminium}

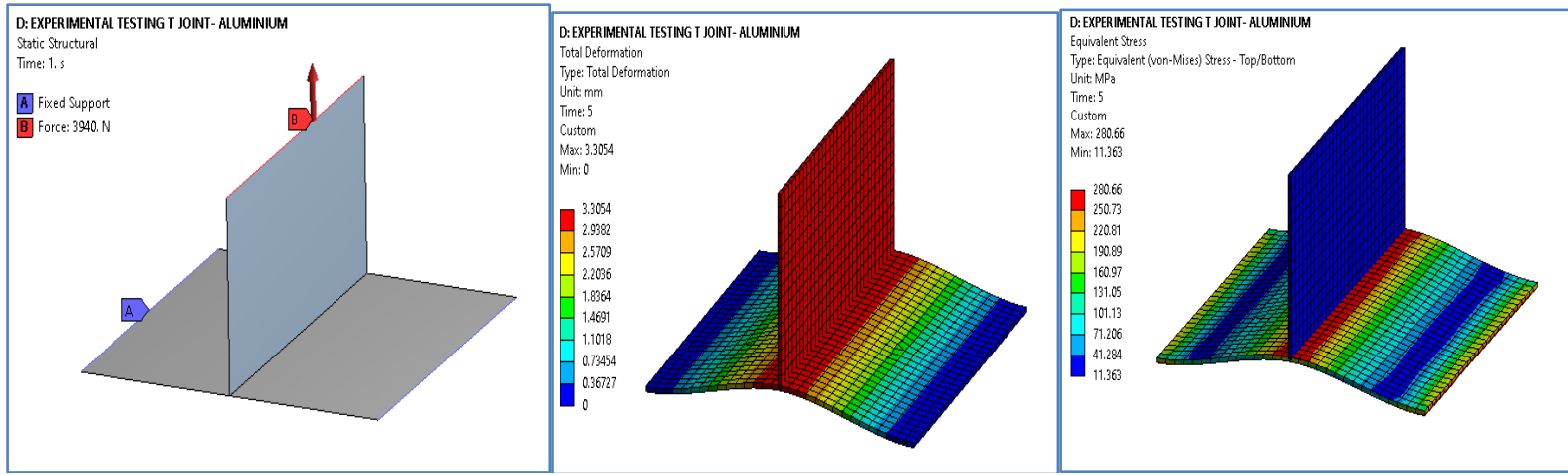

Figure 14: boundary condition Figure 15: total deformation Figure.16: equivalent stress

\subsubsection{For $\mathrm{T}$ joint aluminium with carbon fibre reinforcement}

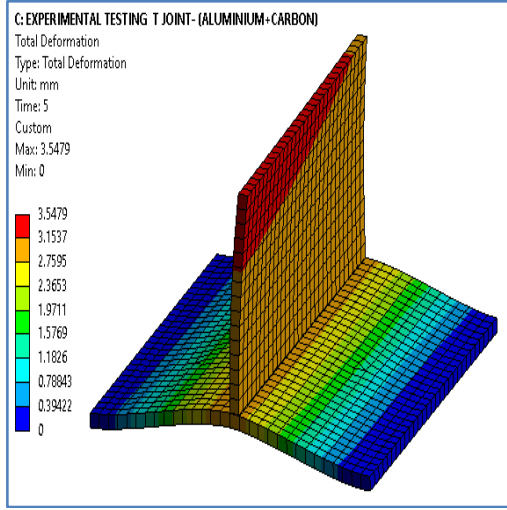

Figure 17: total deformation

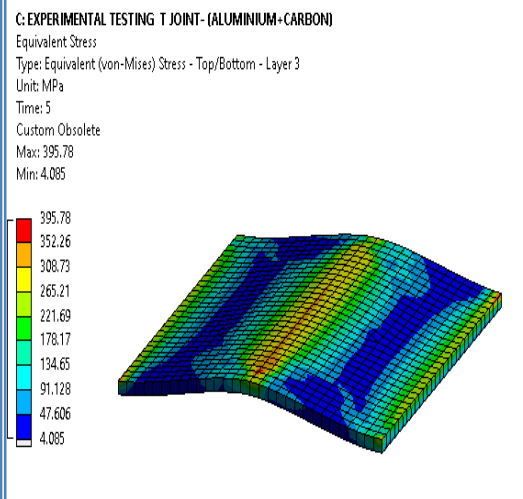

Figure 18: equivalent stress

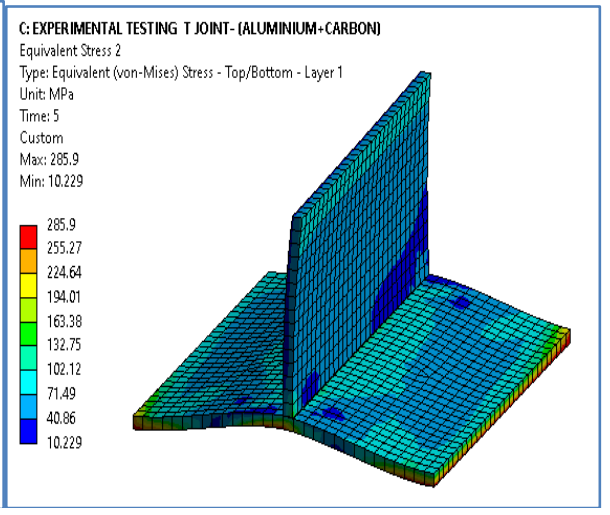

Figure 19: equivalent stress 2

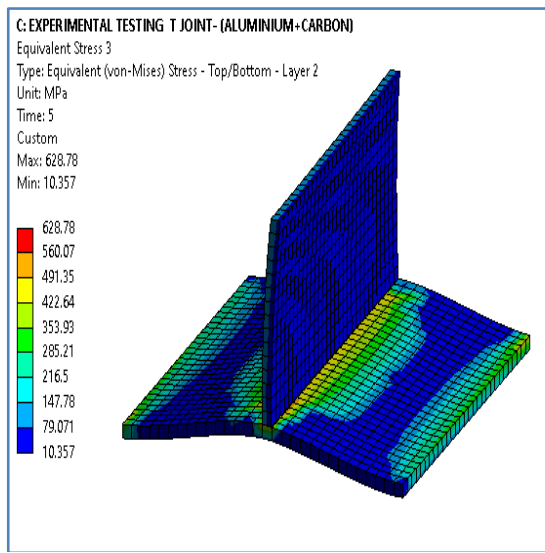

Figure 20: Equivalent stress 3

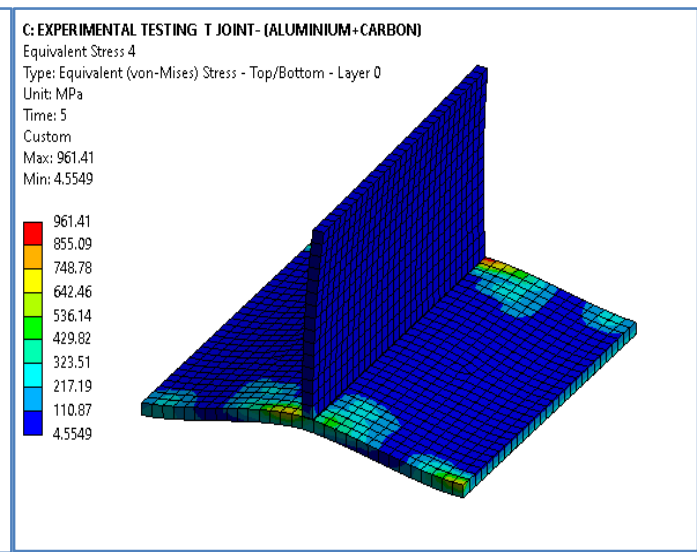

Figure 21: equivalent stress 4

\subsection{Experimental procedure}

- Fixture is manufactured according to component designed. 
- Single force is applied as per FEA analysis and reanalysis is performed to determine strain by numerical and experimental testing.

- Strain gauge is applied as per FEA results to maximum strained region and during experimental testing force is applied as per numerical analysis to check the strain obtained by numerical and experimental results.

- During strain gage experiment two wires connected to strain gage is connected to micro controller through the data acquisition system and DAQ is connected to laptop. Strain gage value is displayed on laptop using DEWESOFT software.

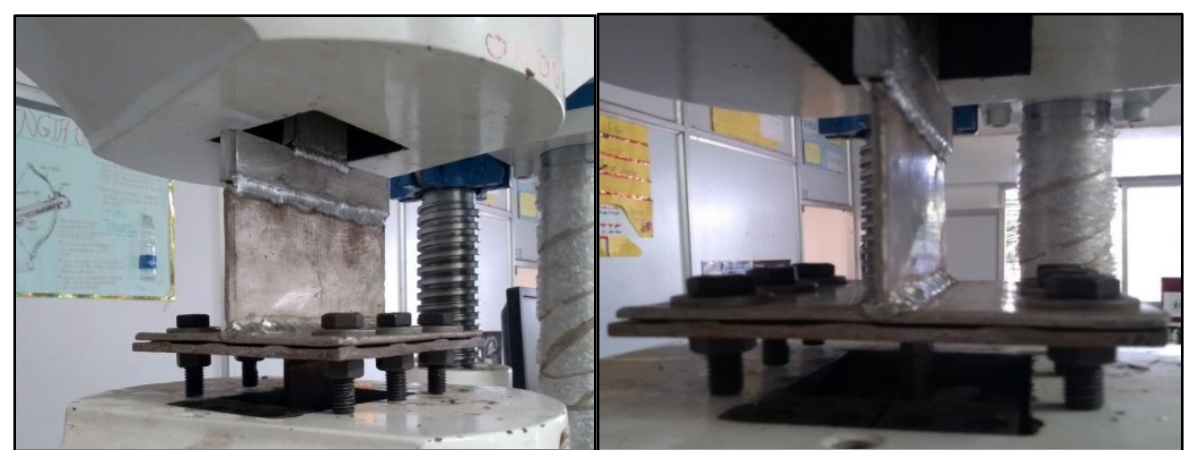

Figure 22: experimental test

Figure 23: experimental testing

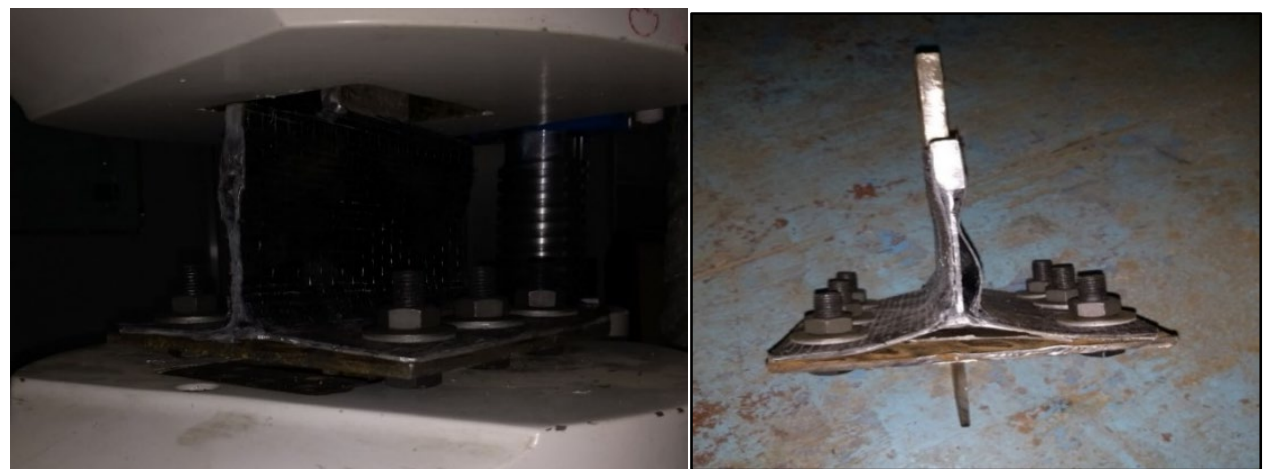

Figure 24: experimental test

Figure 25: Experimental result

\section{Conclusion}

1) In present paper it is observe that reinforce panel can withstand higher load than aluminum panel due to high bonding of epoxy layer.

2) It is observed that $T$ joint with reinforcement of composite layer have improved reaction force to 13.1 $\mathrm{KN}$ compared to existing $\mathrm{T}$ joint with aluminum material with $3.9 \mathrm{KN}$.

3) It is observed that we can use reinforced pane/cleat more effectively over conventional aluminum cleat in automobile /aeronautical industry.

\section{References}

[1] Damage assessment and monitoring of composite ship joints, I. Herszberg, H.C.H. Li , F. Dharmawan , A.P. Mouritz , M. Nguyen, J. Bayandor, Composite Structures 67 (2005) 205-216

[2] Delamination identification of laminated composite plates using a continuum damage mechanics model and subset selection technique, Shen Shang, Gun Jin Yun and PizhongQiao, Smart Mater. Struct. 19 (2010) 055024 
[3] Experimental failure investigation of pull-off tests of single T-stiffened composite specimens, J. Justo, J. Reinoso,_A. Bl'azquez, Composite Structures, Received Date: 22 March 2017, Accepted Date: 25 April 2017

[4] Vibration modal analysis of defects in composite T-stiffened panels, A.P. Herman, A.C. Orifici, A.P. Mouritz, Composite Structures 104 (2013) 34-42

[5] Failure prediction of T-stiffened composite panels subjected to compression after edge impact, Nian Li, Puhui Chen, Composite Structures 162 (2017) 210-226

[6] Impact of composite manufacturing constraints on aerospace stiffened panel design, D. Quinn1 Murphy, m.a. price and $\mathrm{m}$. Mullan, 18th international conference on composite materials 